\title{
Is there a Role for Complementary Medicine in the Management of Patients with Breast Cancer?
}

\author{
Anastasios Liberis* and Konstantinos Dinas \\ Second Department of Obstetrics and Gynecology, Medical School, Aristotle University of Thessaloniki, Hippokration Hospital, Thessaloniki, Greece
} ${ }^{*}$ Corresponding author: Anastasios Liberis, MD, PhD, 18 Osias Xenis street, Thessaloniki, 54250, Greece; Tel: +302310935517; Fax: +302310935517; Email: liberis-t@ hotmail.com

Received: July 01, 2019; Accepted: July 11, 2019; Published: July 20, 2019;

\section{Editorial}

Breast cancer is the most frequent cancer among women and one of the three most common cancers worldwide, along with lung and colon cancer [1]. The survival of patients with breast cancer has increased in recent years due to earlier diagnosis and also due to advances in the treatment of this common disease [2]. However, half of million patients die each year from breast cancer, highlighting the need for further improvements in the management of these patients [3]. Moreover, survivors of breast cancer often exhibit poor quality of life as a result of the complications of treatment [4].

In this context, complementary medicine might be a useful option is selected patients with breast cancer as an addition to the established treatment options. Complementary medicine includes 5 major categories of treatment: a) traditional medical practices, such as whole medical systems, b) mind-body interventions, c) biological substancebased practices, d) manipulative and body-based practices, and e) energy medicine [5]. Several preclinical studies showed that various herbs used in complementary medicine, including turmeric and black cumin, inhibit breast cancer cell proliferation and induce apoptosis [6, 7]. A number of traditional Chinese medications, including Xihuang, shikonin and bakuchiol, also showed anticancer potential in in vitro studies $[8,9]$. However, there are no clinical studies that evaluated the safety and efficacy of these traditional herbs and medications in patients with breast cancer.

Complementary medicine might also have a role in the management of complications of breast cancer treatment. In a randomized, controlled study in 30 patients with breast cancer-related chronic lymphedema, warm acupuncture improved lymphedema, range of motion and quality of life more than placebo treatment and had no adverse effects [10]. In another uncontrolled, pilot study $(n=9)$, Saam acupuncture, a Korean variation of acupuncture, also improved lymphedema [11]. In a meta-analysis of 9 randomized controlled trials $(\mathrm{n}=322)$, tai chi improved handgrip strength and elbow mobility in patients with breast cancer but had no effect on pain, physical, social or emotional well-being or on general health-related quality of life [12]. In another meta-analysis of 13 studies $(n=606)$, arts therapy, including music therapy interventions, various types of art therapy, and dance/movement therapies, improved anxiety but had no effect on depression or quality of life in patients with breast cancer [13]. Several studies also showed that yoga improves anxiety, depression, perceived stress, psychological distress, fatigue, functional, social and spiritual well-being as well as global health-related quality of life in this population $[14,15]$.

In conclusion, complementary medicine appears to be useful for the improvement of well-being in patients with breast cancer. In addition, preclinical data suggest that several traditional herbs might exert antiproliferative and proapoptotic effects on breast cancer cells. However, randomized clinical trials are needed to establish the safety and efficacy of these herbs.

\section{References}

1. Ferlay J, Soerjomataram I, Dikshit R, et al. (2015) Cancer incidence and mortality worldwide: sources, methods and major patterns in GLOBOCAN 2012. Int $J$ Cancer 36: 359-86.

2. Malvezzi M, Carioli G, Bertuccio P, et al (2016) European cancer mortality predictions for the year 2016 with focus on leukemias. Ann Oncol 27: 725-31.

3. Torre LA, Bray F, Siegel RL, Ferlay J, Lortet-Tieulent J, Jemal A (2012) Global cancer statistics, 2012. CA Cancer J Clin 65: 87-108.

4. Edward KL, Chipman M, Giandinoto JA, Robinson K (2019) Quality of life and personal resilience in the first two years after breast cancer diagnosis: systematic integrative review. Br J Nurs 28: S4-S14.

5. Saquib J, Madlensky L, Kealey S, et al (2011) Classification of CAM use and its correlates in patients with early-stage breast cancer. Integr Cancer Ther 10: 138-47.

6. Sun XD, Liu XE, Huang DS (2012) Curcumin induces apoptosis of triple-negative breast cancer cells by inhibition of EGFR expression. Mol Med Rep 6: 1267-70.

7. Sutton KM, Doucette CD, Hoskin DW (2012) NADPH quinone oxidoreductase 1 mediates breast cancer cell resistance to thymoquinone-induced apoptosis. Biochem Biophys Res Commun 426: 421-6.

8. Zheng W, Han S, Jiang S, et al (2016) Multiple effects of Xihuang pill aqueous extract on the Hs578T triple-negative breast cancer cell line. Biomed Rep 5: 559-66.

9. Li L, Chen X, Liu CC, Lee LS, Man C, Cheng SH (2016) Phytoestrogen bakuchiol exhibits in vitro and in vivo anti-breast cancer effects by inducing $\mathrm{S}$ phase arrest and apoptosis. Front Pharmacol 7: 128.

10. Yao C, Xu Y, Chen L, et al (2016) Effects of warm acupuncture on breast cancerrelated chronic lymphedema: a randomized controlled trial. Curr Oncol 23: 27-34.

11. Jeong YJ, Kwon HJ, Park YS, Kwon OC, Shin IH, et al (2015) Treatment of lymphedema with Saam acupuncture in patients with breast cancer: a pilot study. Med Acupunct 27: 206-15.

12. Pan Y, Yang K, Shi X, Liang H, Zhang F, Lv Q. Tai chi chuan exercise for patients with breast cancer: a systematic review and meta-analysis. Evid Based Complement Alternat Med 2015: 535237.

13. Boehm K, Cramer H, Staroszynski T, Ostermann T (2014) Arts therapies for anxiety, depression, and quality of life in breast cancer patients: a systematic review and meta-analysis. Evid Based Complement Alternat Med 2014: 103297. 
Anastasios Liberis (2019) Is there a Role for Complementary Medicine in the Management of Patients with Breast Cancer?

14. Cramer H, Lange S, Klose P, Paul A, Dobos G. Can yoga improve fatigue in breast cancer patients? A systematic review. Acta Oncol 51: 559-60.
15. Cramer H, Lange S, Klose P, Paul A, Dobos G (2012) Yoga for breast cancer patients and survivors: a systematic review and meta-analysis. BMC Cancer 12:412.

Citation:

Anastasios Liberis, Konstantinos Dinas (2019) Is there a Role for Complementary Medicine in the Management of Patients with Breast Cancer? Integr Gyn Obstet J Volume 3(3): 1-2. 